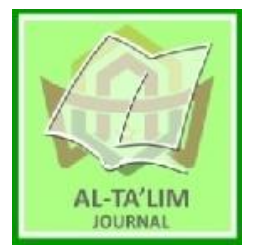

AL-TA'LIM JOURNAL, 27 (1), 2020, (72-79)

(Print ISSN 1410-7546 Online ISSN 2355-7893)

Available online at http://journal.tarbiyahiainib.ac.id/index.php/attalim

\title{
The Selection of Outstanding Teachers to the Determination of Ranking on Professional and Intellectual Managerial Performances
}

Received: 05 ${ }^{\text {th }}$ April 2019; Revised: $06^{\text {th }}$ April 2019; Accepted: $27^{\text {th }}$ February 2020

Permalink/DOI: https://doi.org/10.15548/it.v27i1.602

\section{Rismita *)}

Universitas Muhammadiyah Prof. Dr.

HAMKA Jakarta, Indonesia

E-mail: rismita@uhamka.ac.id

\section{Ihsana El Khuluqo}

Universitas Muhammadiyah Prof. Dr.

HAMKA Jakarta, Indonesia

E-mail: ihsana_khuluqo@uhamka.ac.id

\section{Istaryatiningtias}

Universitas Muhammadiyah Prof. Dr. HAMKA Jakarta, Indonesia

E-mail: iis_ningtias@uhamka.ac.id

\section{Akbar Nadjar Hendra \\ University of York, England \\ E-mail: akbarnadjar@uhamka.ac.id}

\begin{abstract}
The study aims to analyze the selection of outstanding teachers to the determination ranking on professional and intellectual managerial performances. A qualitative research was used where 91 teachers were selected based on the level of education from kindergarten to secondary school and vocational education. The results showed there are three data categories of professional and managerial performances of teachers, namely, high, medium and low. The three categories of data describe the various factors that affect the ability of the management professional and intellectual teachers among the demands of interpersonal of the profession, carrying out the task of teaching a high quality produces professional development, encouragement and motivation from leaders in the school, and a special confidence in the development of professional, as well as using the four dimensions (the assessment of emotion-self, appraisal of emotions of others, use of emotion, and emotion regulation) in improving the performance of teachers and the determination of the personal goals of the teacher in the academic achievement.
\end{abstract}

\section{*) Corresponding Author}

Keywords: Outstanding teacher; professional performance; intellectual performance.

How to Cite: Rismita, R., Khuluqo, I., Istaryatiningtias, I., \& Hendra, A. (2020). The Selection of Outstanding Teachers to the Determination of Ranking on Professional and Intellectual Managerial Performances. Al-Ta lim Journal, 27(1). doi: https://doi.org/10.15548/jt.v27i1.602

\section{INTRODUCTION}

The achievement of the goal of education is the result obtained by the individual against a job in the school by developing the ability of learners. The development of the ability of students is done by the various parties, i.e., supervisors, principals, and teachers. The role of superintendents, principals, and teachers in the school means in the achievement of educational goals related to strategic management and professional abilities and intellectual about their mastery of the knowledge, attitudes, and skills applied in each task.

The application of strategic management and intellectual good by superintendents, principals, and teachers is focused on how to obtain the achievements. The teachers are of high quality can have a positive effect deep in student performance (Sautelle, Bowles, Hattie, \& Arifin, 2015) and other academic achievements are influenced by structural factors, such as socio-economic, and psychological factors. (Claro, Paunesku, \& Dweck, 2016) 
Professional development of teachers that is distributed to students is used to improve student learning. Akiba \& Liang (2016) argued that teachers' continuous engagement in professional learning activities is critical for improvement of their knowledge, instruction, and student learning. It is caused by teachers are indispensable stakeholders in education without whom no country can achieve its educational goals (Salifu, Alagbela, \& Gyamfi Ofori, 2018). In a number of research shows that, the effectiveness of teaching related to skills teaching resources teaching offered is one element that is associated with the performance of the teaching (Ronfeldt, 2015). This is used for sustainability education to develop the ability of affective, cognitive, and practical as a form of in improving the development of development education in each school (Cebrián \& Junyent, 2015).

Outstanding teachers are able to develop the performance of teaching and have high motivations to choose teaching as their careers. The findings of the study by Sharif Upadhyay \& Ahmed (2016) stated that "I like and am interested in teaching" with the average value is 8.47 and Standard Deviation 2.1 and "I have always wanted to be a teacher" with the average value is 6.05 and standard deviation 2.72. The results of the study explain that, the achievement teachers high into the goal in a variety of interventions for student success (Meissel, Parr, \& Timperley, 2016). External factors of the teachers to get the title of outstanding teachers organized by the Department of Education Region II, West Jakarta, aims to improve the motivation and professionalism, enhance competition, increase the appreciation and experience of the teacher, principal, and superintendent. Luthans (2011) suggested that goal setting is the process of motivating employees by establishing effective and meaningful performance targets.

The opinion of the Luthans (2011) explained that the motivation for goal-setting is a factor that affects the level of success of teachers, principals, and supervisors overall in achieving the target of education in the school. Motivation given the Department of Education Region II of the City Administration in Jakarta Barat to teachers, principals, and supervisors, among others: training curriculum 2013 which consisted of 30 schools ( 15 public schools and 15 private schools). The training was held with the hope of every teacher can optimize the implementation of 2013 curriculum with the appropriate.

Priority indicators the selection of outstanding teachers in the Department of Education Region II of the City Administration in Jakarta Barat is done through a selection based on the level of education from Kindergarten (TK) to Upper Secondary School and Vocational School, which has a clarity of purpose to achieve, have the courage which is strong in the act for a policy, have high performance to gain high productivity, as well as give good attention on the other people especially on the students. Department of Education Region II of the City Administration in West Jakarta in achieving the effectiveness of goal-setting education facilitates teachers to improve the work performance. Creswell (2012) revealed that the research helps practitioners evaluate approaches that teachers expect to be successful in educational settings that involves sifting through the research in determining the most fruitful results and suggests improvements for practice. Armed with research results, teachers and other educators become professionals that are more effective.

However, in the selection process, teachers will be included in the selection of outstanding teachers. The qualification criteria required as a participant is not optimal, among other things: the work of teachers (for example: minimum one year of work), socialization in preparing elements of the assessment (portfolio, paper writing action research classes, and others), because the qualification requirements are important in the process of requirement, which shows the development of teacher professionalism. The 
above problems became the reason for the writer to write the article about the selection of outstanding teachers to determination of ranking on professional and intellectual managerial performance. Because in the process of the selection of outstanding, teachers aims to contribute to the identification, understanding, and integrating processes related to each other regarding the role and responsibility of teachers to manage the main activities (teaching and educating) to achieve a common goal, set a target and improve the education system.

\section{METHOD}

The research method used is qualitative research that describes the activities of the selection of outstanding teachers by using sampling technique purposive ie sampling technique based on the purpose of the selection of outstanding teachers as much as 91 teachers divided according to level of education from Kindergarten to Secondary School and Vocational education, starting from preparation, execution (the CAT test, portfolio assessment and assessment of best practice), and reporting the results. The Data used in this study is primary data is data obtained directly from the respondents (participants who are included in the selection of the outstanding teachers). The technique of data analysis is done by describing the quantitative data obtained from the PAINT test, portfolio, and best practice with do a comparison of the data to see the ranking ability of the management professional and intellectual teacher to the selection of outstanding teachers.

\section{RESULT AND DISCUSSION}

The results of the research in the selection of the outstanding teacher by explaining the description of the data about the rankings of professional management and intellectual teachers in the determination of the purpose of education is done by the following stages: the first Stage, the implementation of the CAT test. The material about the PAINT test contains indicators of teachers' competence. Because through these competencies will be realized in the form of mastery of the skills, knowledge and professional attitude in performing their duties and functions as a teacher, as well as the quality of teaching teachers emphasized on teaching practice in the classroom. (Knight et. al., 2015).

The second stage is the assessment of the portfolio. At the stage of the portfolio, among others, contains indicators regarding the creation of the Implementation Plan of Learning (RPP), and the third Stage, the assessment of exposure to best practice on paper or classroom action research (PTK) which made the teacher.

Table 1. Results of Processing the Average Value of the PAINT Test, Portfolio, and Exposure Based on Level of Education

\begin{tabular}{l|c|c|c}
\hline \multicolumn{1}{c}{ The Education Level } & \multicolumn{3}{c}{ End Value } \\
& 1 & 2 & 3 \\
\hline PLB Dikdas & 49.50 & 50.77 & 13.00 \\
\hline Teacher TK (ECE) & 74.97 & 62.27 & 60.90 \\
\hline Teacher SD (Elementary) & 82.77 & 62.93 & 61.27 \\
\hline Teacher SMP & 73.33 & 72.00 & 66.33 \\
\hline Teacher SMA & 79.67 & 66.00 & 57.00 \\
\hline Teacher SMK & 61.67 & 41.00 & 41.33 \\
\hline Headmaster TK & 57.00 & 50.40 & 45.90 \\
\hline Headmaster SD & 66.67 & 68.00 & - \\
\hline Headmaster SMP & 59.63 & 53.30 & 46.53 \\
\hline Headmaster SMA & 64.67 & 69.67 & 53.00 \\
\hline Headmaster SMK & 61.67 & 51.67 & 63.33 \\
\hline
\end{tabular}

Based on the results of processing the data on table 1 above, obtained the highest average value of 82.77 are on the level of Elementary school teachers and the average value of the low amounted to 13.00 there are on the level of teacher PLB. The results of research on the Ranking of the Ability of the Professional Management of Teachers On the Selection of Outstanding Teachers in Department of Education Region II of the City Administration in Jakarta Barat explain descriptively based on the three stages of assessment (PAINT test, Portfolio, and Presentation) have done well. Data acquisition high of $\$ 82.77$ exceed of the average value of the ordinary happened. These values shows that the ranking ability of the management of the professional teacher against the selection of outstanding teachers is 
achieved because the indicator in the assessment of outstanding teachers that are in the portfolio include the level of education of teachers reaches the level of the university, as stated Mincu, namely two major loci that contribute to the development of the teacher as a professional-the university and the school (Mincu, 2015) and the content of the professional development program, the teachers attended was formative assessment is conceived of as a unity of integrated strategies (Andersson \& Palm, 2017).

The opinion of Anderson at the top explaining that the teacher that has the ability to professional management and high intellectual teachers implement new activities that strengthen the practice of teaching in the classroom based on the idea of a great mind in gathering evidence about the knowledge and skills of students and modify the learning activities to get a response better related about student learning needs identified.

The highest average value obtained also gives the sense that teachers who achievement has been achieving effective once held the evaluation stage-the stage of assessment to target the quality of education. Research related to the assessment states that the stability that seems to have characterized teacher evaluation has given way. Sophisticated data systems, achievement growth modeling, and educational reforms that favor tying evaluation, professional development, and dismissal decisions more closely to evidence of teacher effectiveness have led to major changes in statutes governing teacher evaluation (Cohen-Vogel, Little, \& Fierro, 2019). Locke (2013) argued that is associated with the destination is specific goals that have raised performance levels, and individuals with specific goals have shown higher performance than those without goals. The Opinion explains that a goal to achieve the ability of professional management and high intellectual for outstanding teachers is an action that is in accordance with the standards or the benchmarks applied to obtain a ranking of outstanding teachers must have special skills in teaching so as to improve the performance of high compared with teachers who did not excel that has no purpose in his job as a teacher.

On the contrary the lowest value amounted to 13.00 obtained by the teacher based on the average value of the PAINT test, portfolio, and exposure caused due to various influences, for example: the influence of psychological because of the lack of selfconfidence and less creative, as well as the negative influence of the job cycle. Other things that cause the low value of the is teachers ' interest in developing professional skills and intellectual by following a variety of training such as workshops or other activities is still lacking, while such training is very important. Hsieh, Lin, $\mathrm{Li}, \&$ Tsai argued that there are several teacher professional development strategies, such as lecture-based workshops and once-off workshops" (Hsieh, Lin, Liu, \& Tsai, 2019) Purpose to engage teachers in training is coaching, used in a range of practice-based contexts, has been shown to be a powerful means of developing teaching capabilities and practices (Averill, Drake, Anderson, \& Anthony, 2016).

Teacher training is beneficial to improve the teaching practice through professional development conducted by the school duty teacher concerned or through the department of education of the local in the national. Schools identify the strengths and weaknesses of individual teachers and school leaders can make a choice to provide information about professional development activities specifically meet the needs of teachers in the context of the priorities of the school. The context of the priorities of the teacher in achieving success include, there are three parts to the successful process of achieving committed communication. They are agreement of context, alignment of values, and congruence of communication (BoufoyBastick, 2012). Further assessment of the teachers to a certain responsibility in running the task focuses on teacher accountability for the performance of which has consequences 
for the career of a teacher through the selection of outstanding teachers.

Assessment in the selection of outstanding teachers to provide information about the performance of teachers based on tenure to the teaching and education. The assessment involves a team of judges in the selection of outstanding teachers, this type of appraisal may involve external evaluators, and it usually entails consequences for the teacher, such as career advancement, bonus pay, or the possibility of sanctions for underperformance (OECD, 2013). The implementation of a system of teacher assessment in the school is very dependent on the context of school governance and the education department of the local territory, especially on the level of decentralization and autonomy of schools, in this case the Department of Education Region II, West Jakarta and refers to the authority of the education center.
The role of the department of education to the education system hold schools accountable for implementing the policy of quality assurance that is effective without inhibiting creativity and innovation in the selection of outstanding teachers at the level of the region or (DKI Jakarta) and central (National) because it is an important role in applying the system of education that includes the development of standards and instruments as well as methods that will be used and follow up to ensure that teachers in all schools can benefit from evaluation and feedback on the activities of the selection of outstanding teachers. The analysis of the data for the high and low score value in the selection of outstanding teachers based on the criteria of the ideal score. Determination of criteria scores using the ideal mean ideal (Mi) and standard deviation of the ideal (Sdi) as a comparison to know the score. The results of the calculation of the ideal score can be seen in table 2 below:

Table 2. The Scores of Quality Criteria

\begin{tabular}{|c|c|}
\hline Range $=$ Highest Value - Lowest Value & $82.77-13.00=69.77$ \\
\hline Median & 61.27 \\
\hline Q1 & 50.835 \\
\hline Q3 & 66.5 \\
\hline Mean Ideal $(\mathrm{Mi})=1 / 2(\mathrm{X}$ Max $+\mathrm{X}$ Min $)$ & 47.885 \\
\hline Deviation Standard Ideal (Sdi) $=1 / 6(\mathrm{X}$ Max $-\mathrm{X}$ Min $)$ & 11.63 \\
\hline $\mathrm{M}+\mathrm{SD}=$ & $59.52=60$ \\
\hline $\mathrm{M}-\mathrm{SD}=$ & $36.26=37$ \\
\hline $\begin{array}{l}\text { Data Category: } \\
\text { High = } \\
\text { Middle }=\end{array}$ & $\begin{array}{l}=>59.52 \\
=36,26<X<59,52 \\
=<36,26\end{array}$ \\
\hline
\end{tabular}

Table 3. Data Analysis Based on the Ranking of Categories of Data

\begin{tabular}{c|c|c}
\hline Data Category & \multicolumn{2}{c}{ Frequency } \\
\hline High & 18 & 58,06 \\
\hline Middle & 12 & 38,71 \\
\hline Low & 1 & 3,23 \\
\hline
\end{tabular}

Based on table 2 and table 3 above, the score is the Mean of the Ideal (MI) of 47.89 and standard Deviation of the Ideal (Sdi) amounted to 11.63 outlines that the score is to analyze the grouping of data categories that are divided into 3 categories, namely high, medium and low. Category data a high gain level of the frequency of the most abundant that as many as 18 teachers $(58.06 \%)$ of the range of values obtained is greater than 59.52 on Monday. This shows that to see the opportunities in achieving professional and intellectual are the demands of the interpersonal skills of the profession the interpersonal demands of the profession (Atteberry, Loeb, \& Wyckoff, 2017) and higher-quality teaching resulting in increased student learning should be the outcome of professional development (Gess-Newsome et al. 2019). To see sustainable growth as the demands of the profession of each teacher is done with the selection of outstanding teachers through collaborative planning, 
analysis of student work, and goal oriented which leads to interpersonal ability to develop strong personal values (Savitz-Romer, Rowan-Kenyon, \& Fancsali, 2015) and Career teachers should be assessed periodically, with the aim to ensure that the teacher is still in good standing. Motivate teachers due, "the Motivation for the formation and development of professional coaching comes from the demands of modern society. At the individual level, it refers to the need to make conscious life choices (Klarin, 2015) and motivation specifies the reason why people decide to do something (Han \& Yin, 2016) as well as the "Teachers' domainspecific beliefs about teaching and learning constitute an important proximal outcome of Professional Development that is often assumed to mediate PD effects on more distal outcomes, like instructional practices and student learning (Kleickmann, Tröbst, Jonen, Vehmeyer, \& Möller, 2016).

The categories of data being obtained the level of frequency as much as 12 teachers (38.71\%) and the category of data low-gain frequency rate as much as 1 teacher (to $3.23 \%$ ). These Data explain that the low category does not mean the teacher could not manage the activities of teaching and education in a professional and intellectual, but always trying to improve the performance management effectively, because performance management is a continuous process of identifying, measuring, and developing the performance of individuals and teams and aligning performance with the strategic goals of the organization (Aguinis, Gottfredson, \& Joo, 2012) as well as that disclosed in the research of Martin \& Elliot that the growth by way of personal best (PB) goal setting, and its role in academic achievement gains (Martin \& Elliot, 2016) follow-up to the next to cope with the acquisition of low value is to conduct continuous assessment periodically in the selection of outstanding teachers to improve the ability of management professional and intellectual, as well as overcome the shortage, such as that disclosed in related study, evaluation can help programme organisers to identify any weak points and motivate improvements (Saloviita \& Tolvanen, 2017).

The evaluation was done because of the key influences of these lines of work on the quality of teacher preparation, assessment of teaching effectiveness, and competing conceptions of teacher accountability (Darling-Hammond, 2016) and apply the four dimensions of emotional intelligence associated with job performance include the assessment of emotion-self, assessment of other people's emotions, use of emotions, and regulation of emotions) significantly correlated with job performance (Bee Yoke \& Aisyah Panatik, 2015).

\section{CONCLUSION AND RECOMMENDATION}

Based on the results of the study discussed above, with the title of "the Selection of Outstanding Teachers To the Determination of the Ranking of the Ability of Professional Management And Intellectual" in the Department of Education Region II Jakarta City Administration West regarding the assessment of the PAINT test, portfolio, and exposure concluded that the implementation of the selection of outstanding teachers have done well with the acquisition of three data categories (high, medium and low). The third category of data describes the various factors that affect the ability of the management professional and intellectual teachers among the demands of interpersonal of the profession, carrying out the task of teaching a high quality produces professional development, encouragement and motivation from leaders in the school, and the special confidence of the in the development of professional, as well as using the four dimensions (the assessment of emotion-self, appraisal of emotions of others, use of emotion, and emotion regulation) in improving the performance of teachers and the determination of the personal goals of the teacher in the achievement of academic achievement.

This study recommends that the Education Department in each region 
coordinate the selection of high achieving teachers to integrate with each other in the process of developing professional and intellectual abilities of teachers regarding the roles and responsibilities of teachers in managing learning activities to achieve common goals towards improving the education system. Managers and leaders in schools provide motivation and give special confidence in professional development, and are goal-oriented which leads to the development of intrapersonal abilities to develop strong personal values in achieving high performance.

\section{REFERENCES}

Aguinis, H., Gottfredson, R. K., \& Joo, H. (2012). Using performance management to win the talent war. Business Horizons, 55(6), 609-616.

Akiba, M., \& Liang, G. (2016). Effects of teacher professional learning activities on student achievement growth. The Journal of Educational Research, 109(1), 99-110.

Andersson, C., \& Palm, T. (2017). The impact of formative assessment on student achievement: A study of the effects of changes to classroom practice after a comprehensive professional development programme. Learning and Instruction, 49, 92-102.

Atteberry, A., Loeb, S., \& Wyckoff, J. (2017). Teacher Churning: Reassignment Rates and Implications for Student Achievement. Educational Evaluation and Policy Analysis, 39(1), 3-30.

Averill, R., Drake, M., Anderson, D., \& Anthony, G. (2016). The use of questions within in-the-moment coaching in initial mathematics teacher education: Enhancing participation, reflection, and co-construction in rehearsals of practice. Asia-Pacific Journal of Teacher Education, 44(5), 486-503.

Bee Yoke, L., \& Aisyah Panatik, S. (2015). Emotional Intelligence and Job
Performance among School Teachers. Asian Social Science, 11(13), p227.

Boufoy-Bastick, B. (Ed.). (2012). The international handbook of cultures of professional development for teachers: Comparative international issues in collaboration, reflection, management and policy. Strasbourg: Analytrics.

Cebrián, G., \& Junyent, M. (2015). Competencies in Education for Sustainable Development: Exploring the Student Teachers' Views. Sustainability, 7(3), 2768-2786.

Claro, S., Paunesku, D., \& Dweck, C. S. (2016). Growth mindset tempers the effects of poverty on academic achievement. Proceedings of the National Academy of Sciences, 113(31), 8664-8668.

Cohen-Vogel, L., Little, M., \& Fierro, C. (2019). Evidence-Based Staffing in High Schools: Using Student Achievement Data in Teacher Hiring, Evaluation, and Assignment. Leadership and Policy in Schools, 18(1), 1-34.

Creswell, J. W. (2012). Educational research: Planning, conducting, and evaluating quantitative and qualitative research (4th ed). Boston: Pearson.

Darling-Hammond, L. (2016). Research on Teaching and Teacher Education and Its Influences on Policy and Practice. Educational Researcher, 45(2), 83-91.

Gess-Newsome, J., Taylor, J. A., Carlson, J., Gardner, A. L., Wilson, C. D., \& Stuhlsatz, M. A. M. (2019). Teacher pedagogical content knowledge, practice, and student achievement. International Journal of Science Education, 41(7), 944-963.

Han, J., \& Yin, H. (2016). Teacher motivation: Definition, research development and implications for teachers. Cogent Education, 3(1).

Hsieh, F.-P., Lin, H., Liu, S.-C., \& Tsai, C.-Y. (2019). Effect of Peer Coaching on 
Teachers' Practice and Their Students' Scientific Competencies. Research in Science Education.

Klarin, M. (2015). The New Educational Practice of Coaching, and the New Profession of the Coach. Russian Education \& Society, 57(6), 415-428.

Kleickmann, T., Tröbst, S., Jonen, A., Vehmeyer, J., \& Möller, K. (2016). The effects of expert scaffolding in elementary science professional development on teachers' beliefs and motivations, instructional practices, and student achievement. Journal of Educational Psychology, 108(1), 21-42.

Knight, S. L., Lloyd, G. M., Arbaugh, F., Gamson, D., McDonald, S. P., Nolan, J., \& Whitney, A. E. (2015). Reconceptualizing Teacher Quality to Inform Preservice and Inservice Professional Development. Journal of Teacher Education, 66(2), 105-108.

Locke, E. A., \& Latham, G. P. (Eds.). (2013). New Developments in Goal Setting and Task Performance. Routledge.

Luthans, F. (2011). Organizational behavior: An evidence-based approach (12th ed). New York: McGraw-Hill Irwin.

Martin, A. J., \& Elliot, A. J. (2016). The role of personal best (PB) goal setting in students' academic achievement gains. Learning and Individual Differences, 45, 222-227.

Meissel, K., Parr, J. M., \& Timperley, H. S. (2016). Can professional development of teachers reduce disparity in student achievement? Teaching and Teacher Education, 58, 163-173.

Mincu, M. E. (2015). Teacher quality and school improvement: What is the role of research? Oxford Review of Education, 41(2), 253-269.

Ronfeldt, M. (2015). Field Placement Schools and Instructional Effectiveness. Journal of Teacher Education, 66(4), 304-320.

Salifu, I., Alagbela, A. A., \& Gyamfi Ofori, C. (2018). Factors influencing teaching as a career choice (FIT-Choice) in Ghana. Teaching Education, 29(2), 111-134.

Saloviita, T., \& Tolvanen, A. (2017). Outcomes of primary teacher education in Finland: An exit survey. Teaching Education, 28(2), 211-225.

Sautelle, E., Bowles, T., Hattie, J., \& Arifin, D. (2015). Personality, Resilience, SelfRegulation and Cognitive Ability Relevant to Teacher Selection. Australian Journal of Teacher Education, 40(40).

Savitz-Romer, M., Rowan-Kenyon, H. T., \& Fancsali, C. (2015). Social, Emotional, and Affective Skills for College and Career Success. Change: The Magazine of Higher Learning, 47(5), 18-27.

Sharif, T., Upadhyay, D., \& Ahmed, E. (2016). Motivational factors influencing teaching (FIT) as a career: An empirical study of the expatriate teachers in the Emirates. The Journal of Developing Areas, 50(6), 209-225. 